JOURNAL OF TECHNIQUES

Journal homepage: http:/ ljournal.mtu.edu.iq

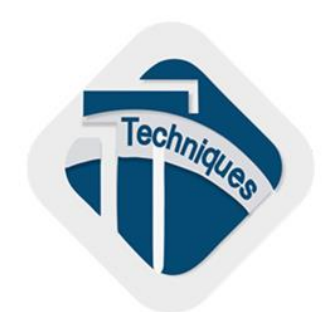

RESEARCH ARTICLE- ENGINEERING

\title{
Urban Expansion Indicators of Cities "Case Study for Arab Cities"
}

\author{
Nabil T. Ismael ${ }^{* 1}$ \\ ${ }^{1}$ University of Diyala, College of Engineering, Architectural Engineering Department, Diyala, Iraq \\ * Corresponding author, E-mail: nabiltaha2001@ gmail.com ; nabiltaha2001@engineering.uodiyala.edu.iq
}

\begin{tabular}{ll}
\hline Article history & Abstract \\
\hline Received & $\begin{array}{l}\text { Urban population growth requires an appropriate and suitable place for future population to cope with the expected } \\
\text { urban expansion of major cities in developing countries, and to identify an indicator urban expansion to guide } \\
\text { planners, architects and decision makers, and help them reduce negative effects of city expansion with improvement } \\
\text { in the ability to live in cities. The density (population and building), fragmentation (saturation and openness) and } \\
\text { compactness (proximity and cohesion) are the most important indicators of urban expansion of cities, which gives a } \\
\text { clear perception of how city expands and possibility of adopting the most suitable ones when updating or preparing } \\
\text { master lans. Most cities, especially Arab ones, suffer from excessive urban expansion, resulting in various urban } \\
\text { problems affecting quality of life, services and city performance, which is the problem of research. This research is } \\
\text { aimed at identifying factors influencing urban expansion of cities in developing countries when preparing for their } \\
\text { future expansion, by analyzing the indicators of urban expansion of a set of cities to reach appropriate indicators for } \\
\text { urban expansion sustainable future of the city to ensure orderly development of cities and make them more } \\
\text { productive, more comprehensive and sustainable in upcoming decades. }\end{array}$ \\
Published &
\end{tabular}

Keywords: Urban Expansion; Density; Fragmentation; Compactness.

(O2019 Middle Technical University. All rights reserved.

\section{Introduction}

The continuity of population growth in cities, especially developing countries, requires the provision of a suitable place for the population as well as the provision of services to them in accordance with the sustainable trends that take into account the environmental, social and economic dimensions. It works to achieve the well-being and social justice for the community with a liveable urban environment, and this requires knowledge of urban expansion indicators that help to reduce urban problems and guide the growth of the city in a sustainable way.

\section{The theoretical framework for urban expansion}

\section{2- 1 Urban expansion}

There is a reluctance to deal with urban expansion. Many people believe that cities consume enough land, and that all future construction should take place within the existing urban environmental footprint, while others oppose urban expansion and call for the preservation of municipal boundaries and limiting mobility, which reduce traffic congestion, conserve energy, minimize air pollution, and protect urban agricultural land. Some 95\% of urban expansion in the next decades will take place in the developing world, mainly in developing cities. Rapid urbanization is exerting increasing pressure on fresh water supplies, sewage, living environment and public health [1].

\section{2-2 Urban expansion elements}

The city consists of a group of elements that interact with each other and which grow and expand continuously or fade due to different causes. These elements are: 
1) Population: The increasing number of urban populations on a continuous basis needs to expand cities and provide land to accommodate these population increases and therefore need to develop plans and policies to determine the trends of urban expansion to commensurate with population needs. Over half of the world's population (54 percent) now live in urban areas, up from $30 \%$ in 1950. The coming decades will bring further profound changes to the size and spatial distribution of the global population such that the world's population in 2050 is projected to be $66 \%$ urban. The global urban population is projected to grow by 2.5 billion urban dwellers between 2014 and 2050, with nearly $90 \%$ of the increase concentrated in Asia and Africa [2].

2) Urban Extent: It represents the city's master plan boundary. The annual population growth rate is compared with the annual change of the urban extent to determine the type of urban expansion of the city and comparing the annual change of the built-up area, open space and the urban extent to the planning directions of urban expansion and how to deal with these areas. The principal objective of measuring urban extent and expansion is to provide concise information to interested stakeholders which will ground the study, the debate, and the decisions concerning these issues in empirical facts [3].

3) Build-up Area: It includes all non-vegetative, human-constructed elements, such as roads, buildings, runways, etc. (i.e. humanmade surfaces), and 'dominated' implies coverage greater than 50\% of a given landscape unit (the pixel) [4]. the built-up area of developing-country cities will increase to more than 600,000 square kilometers by 2030. In other words, by 2030 these cities can be expected to triple their land area, with every new resident converting, on average, some 160 square meters of non-urban to urban land during the coming years. the built-up area of industrialized-country cities will increase to some 500,000 square kilometers by 2030. In other words, by 2030 these cities can be expected to increase their populations by $20 \%$ and their land areas by 2.5 times, with every new resident converting, on average, some 500 square meters of non-urban to urban land [5].

\section{2-3 Urban expansion indicators}

The most important indicators of urban expansion of cities are:

1) Density: It measures the urban extent and built-up area of the city, which is the ratio of the number of persons per unit of area. Urban Extent density is measured by the total population of the city and its urban extent and the built-up area density. Urban extent density is always less than the built-up area density because of the presence of more open space in the city. Higher density of cities can bring efficiency gains. It is expected that technological innovation will further help reduce resource and energy consumption and thereby reduce the overall adverse environmental impact per capita of cities [6]. Key concepts of density and sustainable developments include issues of transport and compactness which would involve a discussion about the desired 'optimal density', mixed land uses, diversity and the use of appropriate technology, such as solar design, greening and re-naturing of cities and a reduction of the use of finite resources [7].

2) Fragmentation: Defined as the relative share of open space in the urban landscape, is now in decline. Using multiple regression models, we find that larger cities are less fragmented, higher-income cities are more fragmented, higher levels of car ownership tend to reduce fragmentation, and cities that constrain urban development are less fragmented than cities that do not. We recommend that making room for urban expansion in rapidly growing cities should take into account their expected fragmentation levels [8]. It is the average share of a one-square kilometer urban neighborhood that is occupied by open space [9]. As the area of fragmentation increases, the urban extent density less, distance between sites in the city increased and more scattered to open areas in the city. Spatial fragmentation causes problems in the city's urban structure. Urban mobility is affected, restricting the movement patterns in the city, which in turn decreases the use of various activities in the city [10].

Fragmentation includes two indicators. The first is the Saturation index, which is the proportion of the built-up area within the city's urban extent and its total urban extent, and the second is Openness Index that measures the average percentage of non-built up area in a $1 \mathrm{~km}$ diameter circle surrounding each built-up pixel in the city [11]. The values for each of these indicators range from 0 to 1 . The saturation index is at the maximum when the urban extent doesn't contain open space at all. The openness index is at the maximum when the urban extent includes only open space.

3) Compactness: It was defined as the ratio of the consolidated built-up area within the circle and buildable area within the circle [12]. The form that reduces the average distance from any point inside to its center, or the form that reduces the average distance between all points within them.

Compactness includes two indicators. The first is the Proximity index, which is the ratio of the average linear distance of all points in a circle equal to the city center, and the average linear distance from all points in the urban extent to the city center. The second is the Cohesion index, which is the ratio of the average linear distance of all points to all other points in an equal circle, and the average linear distance from all points to all other points in the urban extent. The value of both indicators varies between 0 and 1 , the higher values corresponding to the urban extent are closer to the circular form.

Urban cohesion is related to various factors, including environmental, economic and social aspects. An additional fourth aspect involves physical and functional factors, and is highly related to the urban structure. This fourth factor affects the continuity and accessibility of space. Taking this factor into account allows better understanding of the urban space with its various functions, and makes it possible to influence movement patterns and links between the urban functions. In particular, the programming, planning and designing of urban public spaces has a strong impact on the urban sustainability and thereby also the urban cohesion [13]. 


\section{2-4 The benefits of urban expansion indicators}

The most important benefits of using urban expansion indicators are:

- knowledge of planned or uncontrolled urban expansion.

- know the ratio of urban land before and after urban expansion.

- Knowledge of the sustainability of cities.

- Know the ratio of the built-up area to the percentage of open spaces.

- Empirical data of urban expansion and its main characteristics, and their change over time, can provide an urgent basis for understanding the global and historical contexts of urban expansion.

- Explain the underlying forces that drive and form urban expansion.

\section{Results and discussions}

The indicators of density, fragmentation and compactness for nine main Arab cities were measured to analyze the trends of the urban expansion for the city and how to absorb population growth during three different time periods, including the population and urban area of the city, as follows:

\section{3-1 Baghdad city - Iraq}

Table 1 presents the most important indicators of Baghdad's urban expansion (Fig. 1) noting the following:

1) Urban extent: Baghdad's annual population growth rate was $2.2 \%$, and the annual change in the built-up area increased by $2.7 \%$ by exceeding the open areas in the semi-urban and rural areas, which showed an annual change of $-1.4 \%$ and $-0.7 \%$, as well as shrinking of open areas by $-1.4 \%$. I note that the urban extent of Baghdad city has increased very little by $0.9 \%$ per annum, which indicates the preservation of the city's master plan boundaries and the significant lack of expansion as a result of the absence of an update of the master plan since 2000.

2) Population density: I note that the density of population in the built-up areas has increased by $0.2 \%$, and in the urban extent has increased by $1.2 \%$. This is an evidence of the city's horizontal expansion, building on open and green areas, and the low population density of Baghdad.

3) Fragmentation: The saturation index shows its increase over time by $1.1 \%$ annually due to the filling of urban spaces in the city and no vertical expansion. The openness index decreased by $-2.6 \%$, this is evident due to overtaking of the open areas surrounding the built area.

4) Compactness: The convergence and cohesion index shows a small increase of $0.2 \%$ and $0.3 \%$, and the two indicators indicate that the city's shape approximates the circular form by more than $80 \%$, which means an equal distribution of access to the city center from all over the city.

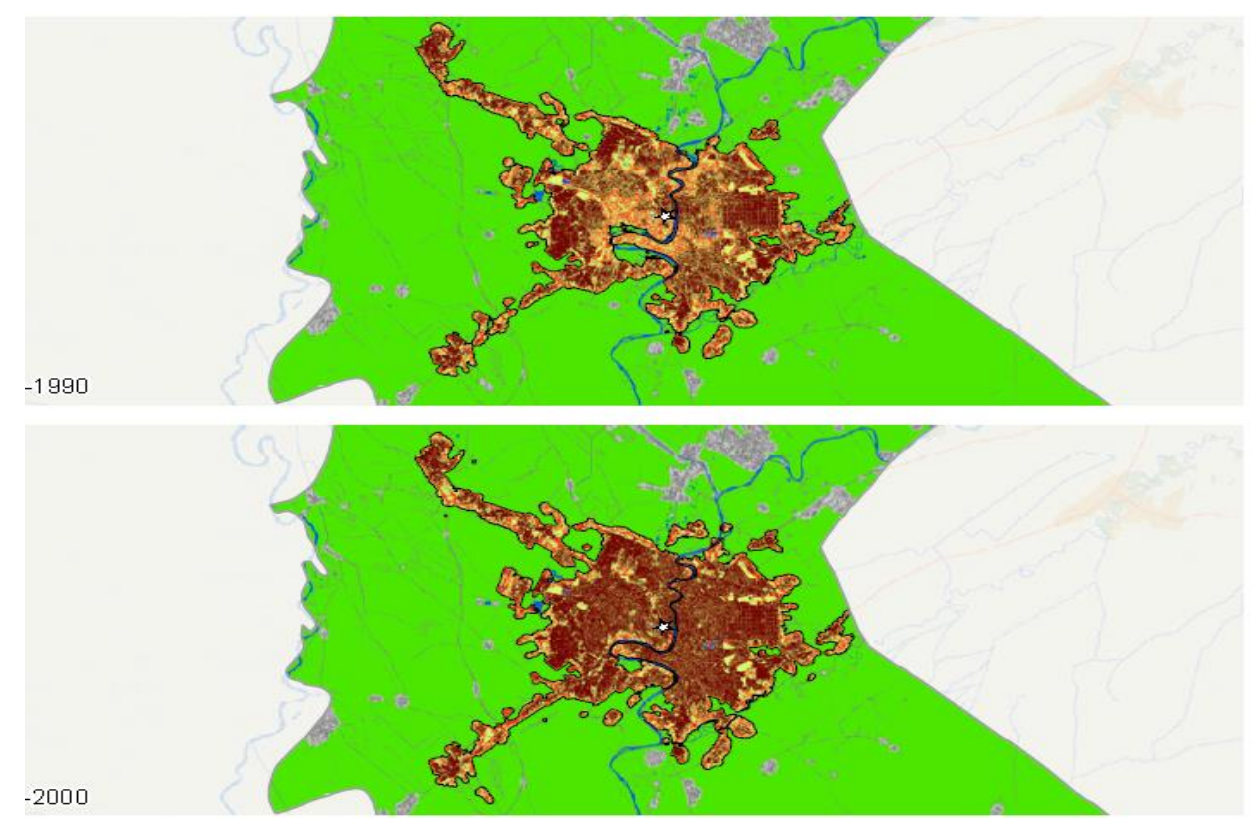




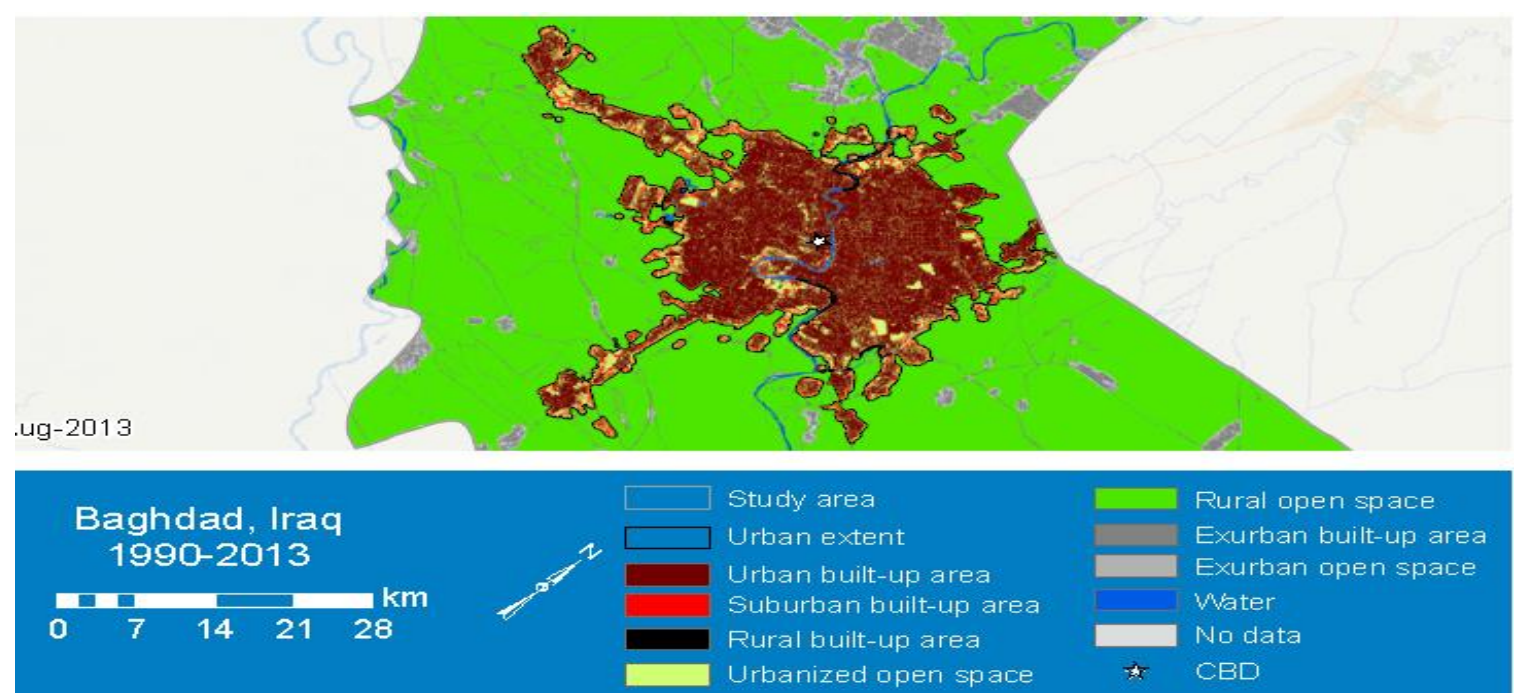

Fig. 1. Baghdad master plan within three time periods [14]

Table 1 Indicators of urban expansion of Baghdad city [14]

\begin{tabular}{|c|c|c|c|c|c|}
\hline Indicators & & 1990 & 2000 & 2013 & $\begin{array}{l}\text { Amount of annual change } \\
\text { (\%) (2000-2013) }\end{array}$ \\
\hline Population (person) & & $2,837,103$ & $3,985,382$ & $5,279,193$ & 2.2 \\
\hline \multirow{4}{*}{ Build-Up Area (ha) } & Urban & 23,812 & 34,312 & 48,597 & 2.7 \\
\hline & Suburban & 10,475 & 8,618 & 7,170 & -1.4 \\
\hline & Rural & 580 & 573 & 522 & -0.7 \\
\hline & Total & 34,867 & 43,502 & 56,288 & 2 \\
\hline Open Space Area (ha) & & 27,413 & 25,284 & 21,207 & -1.4 \\
\hline Urban Extent Area (ha) & Total & 62,280 & 68,786 & 77,496 & 0.9 \\
\hline \multirow{2}{*}{ Population Density (person/ha) } & Built up & 81.4 & 91.6 & 93.8 & 0.2 \\
\hline & Urban extent & 45.6 & 57.9 & 68.1 & 1.2 \\
\hline \multirow{2}{*}{ Fragmentation } & $\begin{array}{l}\text { Saturation } \\
\text { index }\end{array}$ & 0.56 & 0.63 & 0.73 & 1.1 \\
\hline & $\begin{array}{l}\text { Openness } \\
\text { index }\end{array}$ & 0.41 & 0.34 & 0.24 & -2.6 \\
\hline \multirow{2}{*}{ Compactness } & Proximity index & 0.79 & 0.82 & 0.84 & 0.2 \\
\hline & Cohesion index & 0.77 & 0.78 & 0.81 & 0.3 \\
\hline
\end{tabular}

\section{3-2 Riyadh city - Saudi Arabia}

Table 2. present the most important indicators of Riyadh's urban expansion (Fig. 2) noting the following:

1) Urban extent: The population growth rate was $4 \%$, and the annual change in the urban extent was $5 \%$, which refers to the horizontal expansion of the city. The amount of change for the built-up area was 5.7\% and for the open space $3.1 \%$, this refers to the dominance of the areas built to the calculation of the open areas and the overrun. The amount of change in the built-up area indicates an increase in urban-up areas by $6.2 \%$ and suburban area by $3 \%$, while the built-up area in the rural decreased by $6.1 \%$, which indicates an increase of urbanization in the city.

2) Population density: Table (A) indicates a decrease in the density of the built area by $-1.8 \%$ and the urban extent by $-1 \%$ as a result of the urban sprawl of the city.

3) Fragmentation: The saturation index refers to an increase of $0.7 \%$ with the openness index decreasing by- $2.4 \%$ as a result of the increase of the built-up area by more than the open space areas and the filling of urban spaces in the built-up area in the city.

4) Compactness: The proximity and cohesion index indicates a slight increase of $0.3 \%$, the city's urban form convergence of the circular shape and the accessibility of all parts of the city by $90 \%$. 

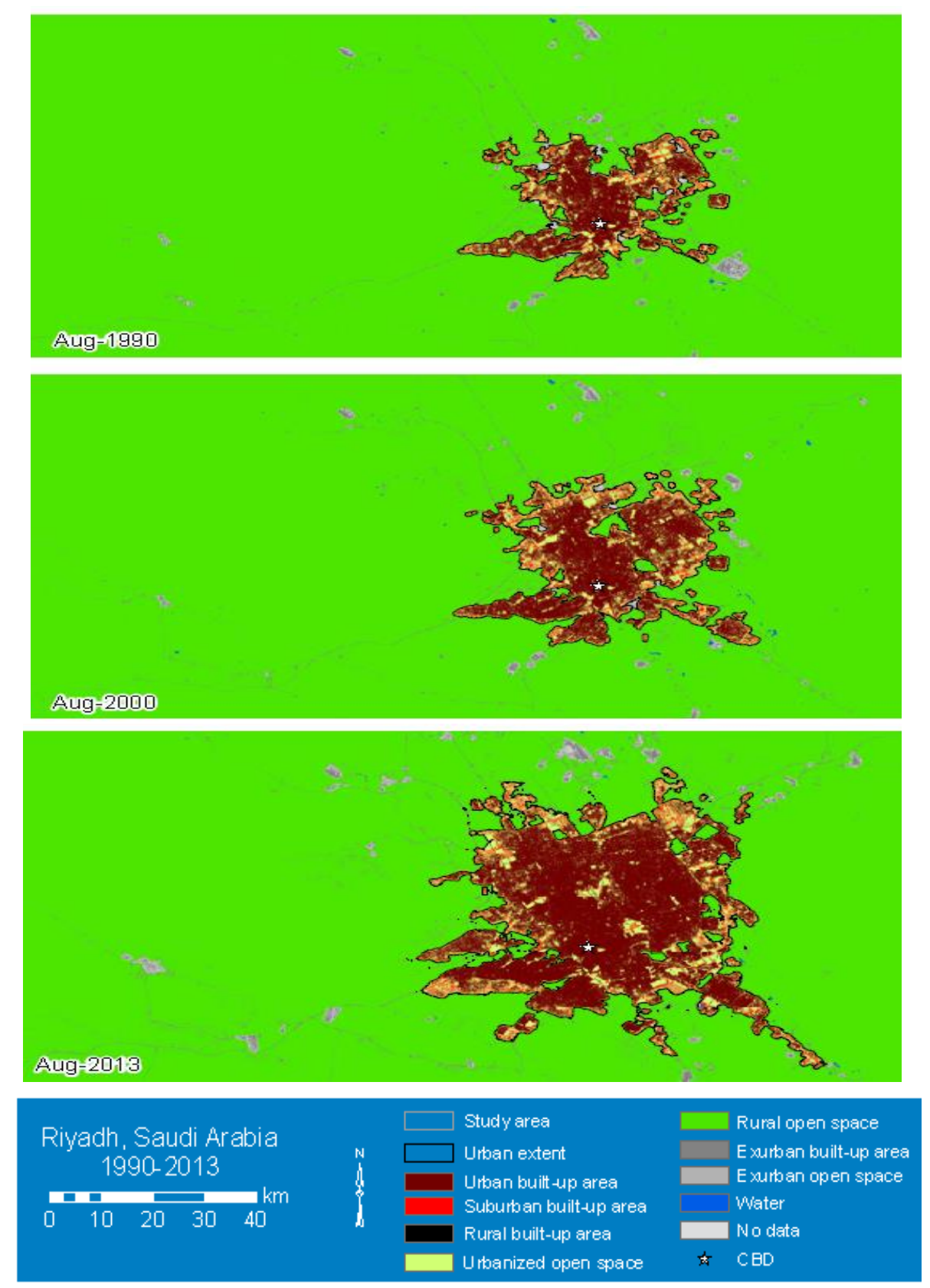

Fig. 2. Riyadh master plan within three time periods [14] 
Table 2 Indicators of urban expansion of Riyadh city [14]

\begin{tabular}{|c|c|c|c|c|c|}
\hline Indicators & & 1990 & 2000 & 2013 & $\begin{array}{l}\text { Amount of annual change } \\
(\%)(2000-2013)\end{array}$ \\
\hline Population (person) & & $2,210,740$ & $3,311,356$ & $5,552,240$ & 4 \\
\hline \multirow{4}{*}{ Build-Up Area (ha) } & Urban & 24,251 & 37,741 & 84,857 & 6.2 \\
\hline & Suburban & 5,631 & 7,255 & 10,778 & 3 \\
\hline & Rural & 424 & 500 & 226 & -6.1 \\
\hline & Total & 30,305 & 45,495 & 95,861 & 5.7 \\
\hline Open Space Area (ha) & & 15,582 & 21,315 & 31,945 & 3.1 \\
\hline Urban Extent Area (ha) & Total & 45,887 & 66,810 & 127,805 & 5 \\
\hline \multirow{2}{*}{ Population Density (person/ha) } & Built up & 72.9 & 72.8 & 57.9 & -1.8 \\
\hline & Urban extent & 48.2 & 49.6 & 43.4 & -1 \\
\hline \multirow[t]{2}{*}{ Fragmentation } & $\begin{array}{l}\text { Saturation } \\
\text { index }\end{array}$ & 0.66 & 0.68 & 0.75 & 0.7 \\
\hline & Openness index & 0.29 & 0.26 & 0.19 & -2.4 \\
\hline \multirow{2}{*}{ Compactness } & Proximity index & 0.83 & 0.88 & 0.91 & 0.3 \\
\hline & Cohesion index & 0.82 & 0.87 & 0.9 & 0.3 \\
\hline
\end{tabular}

3-3 Sana'a city - Yemen

Table 3. Presents the most important indicators of Sana'a urban expansion Fig. 3 noting the following:

1) Urban extent: The population growth rate of Sana'a city was $2.8 \%$, and the annual change in the urban extent was $5.6 \%$, indicating that the city is expanding horizontally and increasing its area.

2) Population density: The population density in the built-up area is reduced by a low of $-0.7 \%$ and the urban extent by- $2.8 \%$ due to the city's urban sprawl, expansion towards the edges of the city and increased open space in the city.

3) Fragmentation: Note that the saturation index is reduced by $-2.1 \%$ due to the fragmentation of the fabric due to the increase in open space, thus increasing the opening index of the city by $3.8 \%$ due to the increase of the open spaces by $11.3 \%$.

4) Compactness: The proximity and cohesion index indicates a very slight decrease of $-0.1 \%$ as a result of urban sprawl and the linear expansion of Sana'a city and moving away from the circular shape to be a growing city parties. 


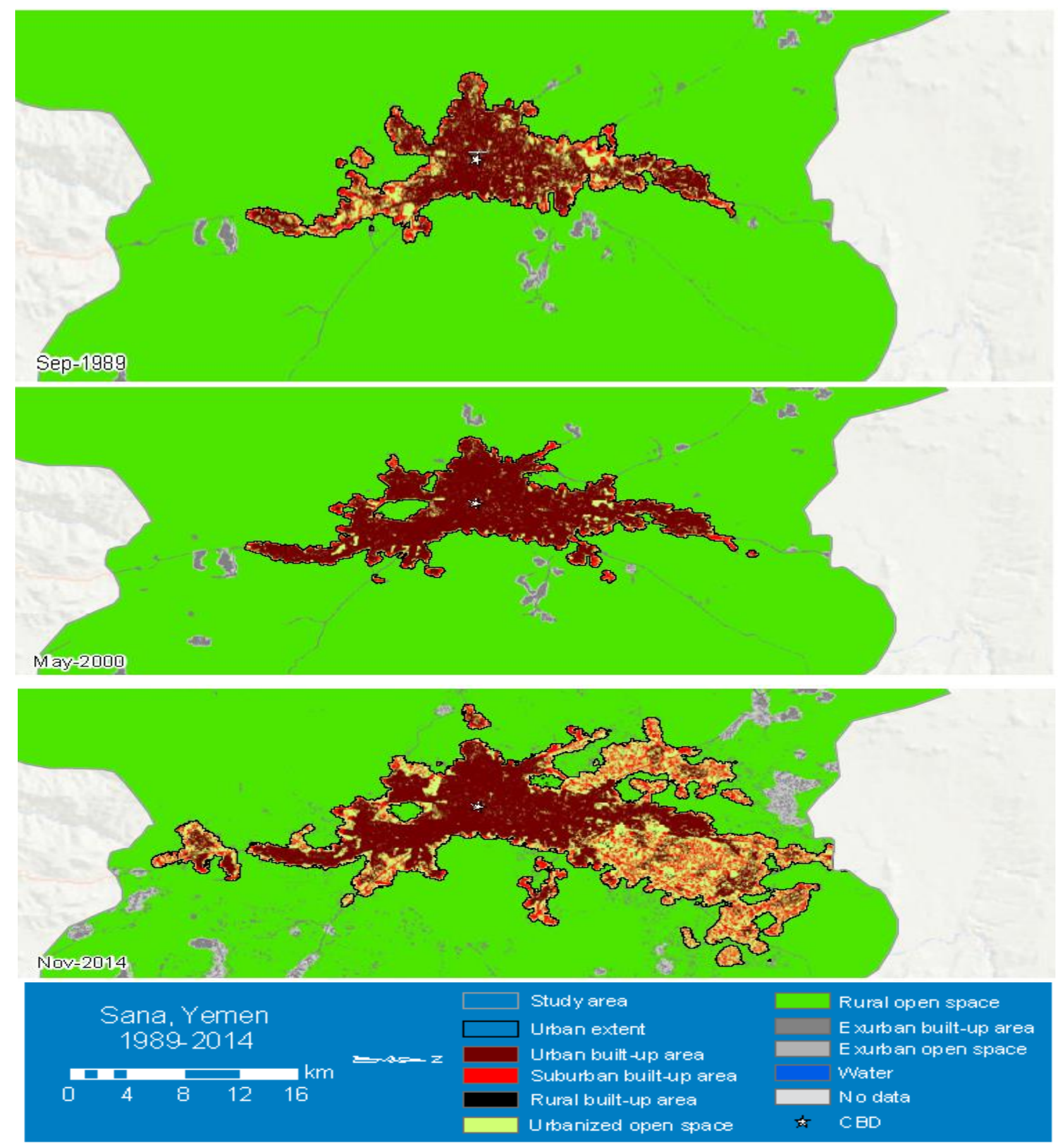

Fig. 3. Sana'a master plan within three time periods, Angel [14] 
Table 3 Indicators of urban expansion of Sana'a city [14]

\begin{tabular}{|c|c|c|c|c|c|}
\hline Indicators & & 1989 & 2000 & 2014 & $\begin{array}{l}\text { Amount of annual change } \\
(\%)(2000-2014)\end{array}$ \\
\hline Population (person) & & 929,646 & $1,513,993$ & $2,258,322$ & 2.8 \\
\hline \multirow{4}{*}{ Build-Up Area (ha) } & Urban & 7,124 & 12,120 & 15,395 & 1.6 \\
\hline & Suburban & 1,819 & 1,257 & 6,302 & 11.1 \\
\hline & Rural & 109 & 90 & 416 & 10.5 \\
\hline & Total & 9,051 & 13,467 & 22,113 & 3.4 \\
\hline Open Space Area (ha) & & 4,049 & 2,769 & 14,277 & \\
\hline Urban Extent Area (ha) & Total & 13,100 & 16,236 & 36,390 & 5.6 \\
\hline \multirow{2}{*}{ Population Density (person/ha) } & Built up & 102.7 & 112.4 & 102.1 & -0.7 \\
\hline & Urban extent & 71.0 & 93.2 & 62.1 & -2.8 \\
\hline \multirow[t]{2}{*}{ Fragmentation } & $\begin{array}{l}\text { Saturation } \\
\text { index }\end{array}$ & 0.69 & 0.83 & 0.61 & -2.1 \\
\hline & Openness index & 0.3 & 0.18 & 0.31 & 3.8 \\
\hline \multirow{2}{*}{ Compactness } & Proximity index & 0.67 & 0.71 & 0.7 & -0.1 \\
\hline & Cohesion index & 0.65 & 0.7 & 0.69 & -0.1 \\
\hline
\end{tabular}

\section{3-4 Cairo city - Egypt}

Table 4. Presents the most important indicators of Cairo's urban expansion (Fig. 4) noting the following:

1) Urban extent: Cairo's annual population growth rate was $2.7 \%$, and the city's urban expansion rate was $8.5 \%$, which means that the city's area increase is more than 3 times the rate of population growth. The table shows that the increase in area was mainly concentrated in the expansion of rural areas by $10.2 \%$ and suburban by $11.5 \%$, as well as the built up by $6.3 \%$.

2) Population density: The table shows that the population density in the built-up area decreased by $4.4 \%$ and the urban extent by $5.7 \%$ due to the increase of open areas by $12.2 \%$ in the built-up area and the urban extent due to the high density of the city and the attempt to reduce urban overcrowding.

3) Fragmentation: The saturation index shows a decrease of $1.4 \%$ as a result of increased open areas in the built-up area, and the disintegration of the city's urban fabric. The openness index increased its annual rate by $2.6 \%$.

4) Compactness: The proximity and cohesion index shows a very small increase of $0.1 \%$ and an attempt to shift from the linear expansion of the city with the Nile River to a circular expansion of up to $70 \%$. 

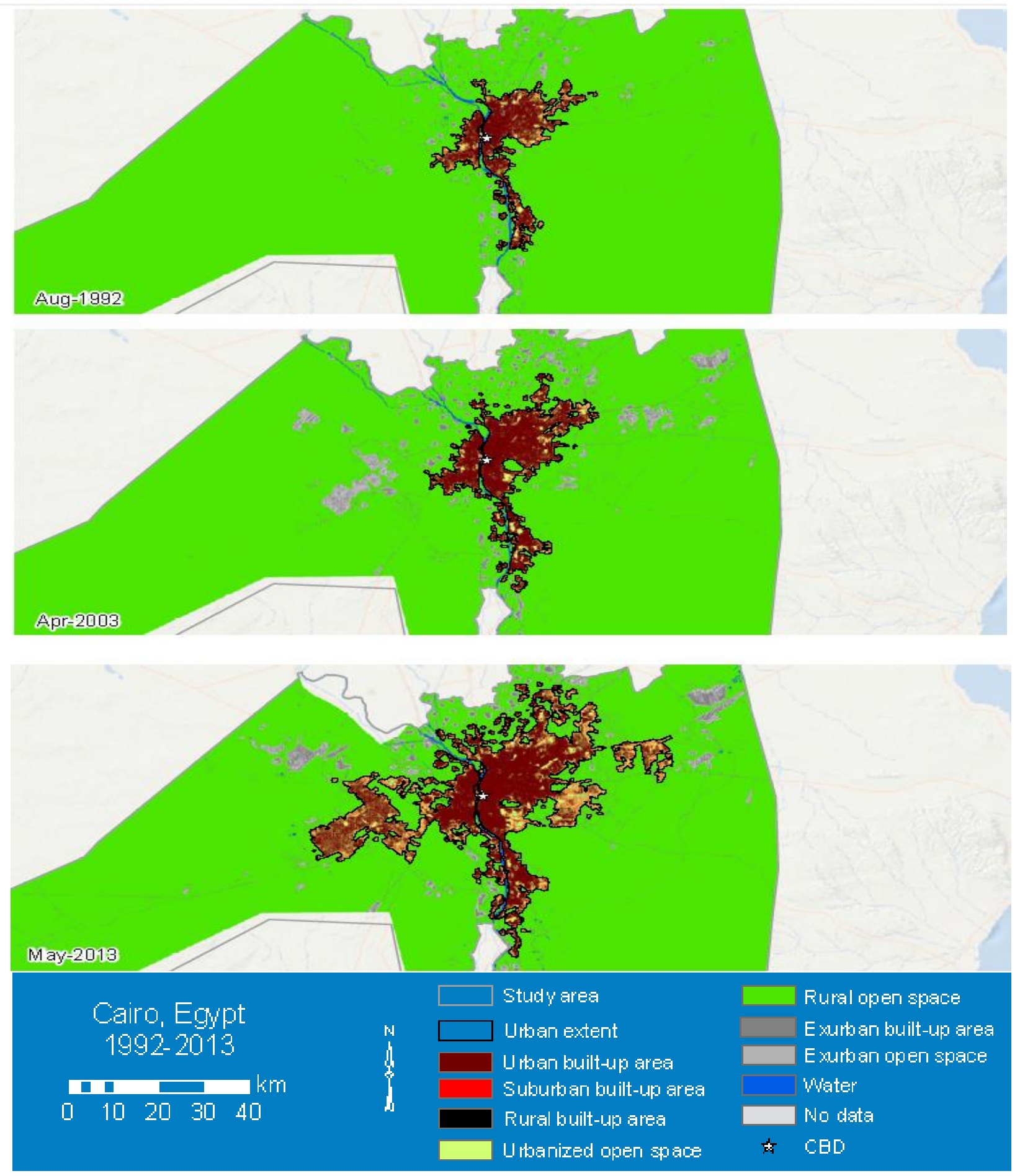

Fig. 4. Cairo master plan within three time periods, Angel [14] 
Table 4 Indicators of urban expansion of Cairo city [14]

\begin{tabular}{|c|c|c|c|c|c|}
\hline Indicators & & 1992 & 2003 & 2013 & $\begin{array}{l}\text { Amount of annual change } \\
\text { (\%) (2003-2013) }\end{array}$ \\
\hline Population (person) & & 9621784 & 11928479 & 15734934 & 2.7 \\
\hline \multirow{4}{*}{ Build-Up Area (ha) } & Urban & 24381.18 & 39689.37 & 74782.26 & 6.3 \\
\hline & Suburban & 4999.59 & 5386.59 & 17099.55 & 11.5 \\
\hline & Rural & 336.15 & 431.64 & 1210.77 & 10.2 \\
\hline & Total & 29,717 & 45,508 & 93,093 & 7.1 \\
\hline Open Space Area (ha) & & 11,486 & 12,665 & 43,303 & 12.2 \\
\hline Urban Extent Area (ha) & Total & 41,203 & 58,172 & 136,396 & 8.5 \\
\hline \multirow{2}{*}{ Population Density (person/ha) } & Built up & 323.8 & 262.1 & 169.0 & -4.4 \\
\hline & Urban extent & 233.5 & 205.1 & 115.4 & -5.7 \\
\hline \multirow[t]{2}{*}{ Fragmentation } & $\begin{array}{l}\text { Saturation } \\
\text { index }\end{array}$ & 0.72 & 0.78 & 0.68 & -1.4 \\
\hline & Openness index & 0.26 & 0.2 & 0.26 & 2.6 \\
\hline \multirow{2}{*}{ Compactness } & Proximity index & 0.67 & 0.7 & 0.71 & 0.1 \\
\hline & Cohesion index & 0.66 & 0.68 & 0.69 & 0.1 \\
\hline
\end{tabular}

\section{3-5 Alexandria city - Egypt}

Table 5 presents the most important indicators of Alexandria's urban expansion (Fig. 5) noting the following:

1) Urban extent: The population growth rate of Alexandria was $2.3 \%$ and the urban extent rate was $2.8 \%$. This indicates a greater urbanization than the population growth rate, with the increase of the open space by $3.2 \%$, as well as the increase of the built-up areas in the suburban and rural areas by $3.4 \%$ and $5.2 \%$.

2) Population density: Alexandria city is very densely populated in the built-up area and the urban extent. I observe a decrease in the density of $-0.4 \%$ and $-0.5 \%$ as a result of increasing the area of urban extent and open space in large proportions.

3) Fragmentation: The saturation and openness index indicates the stability of the urban fabric and its constant expansion with a very slight decrease of- $0.1 \%$.

4) Compactness: The proximity and cohesion index indicates an increase in urban sprawl, a reduction of the indexes by- $0.3 \%$ and$0.6 \%$, and the city is expanding linearly and far from the circular shape. 

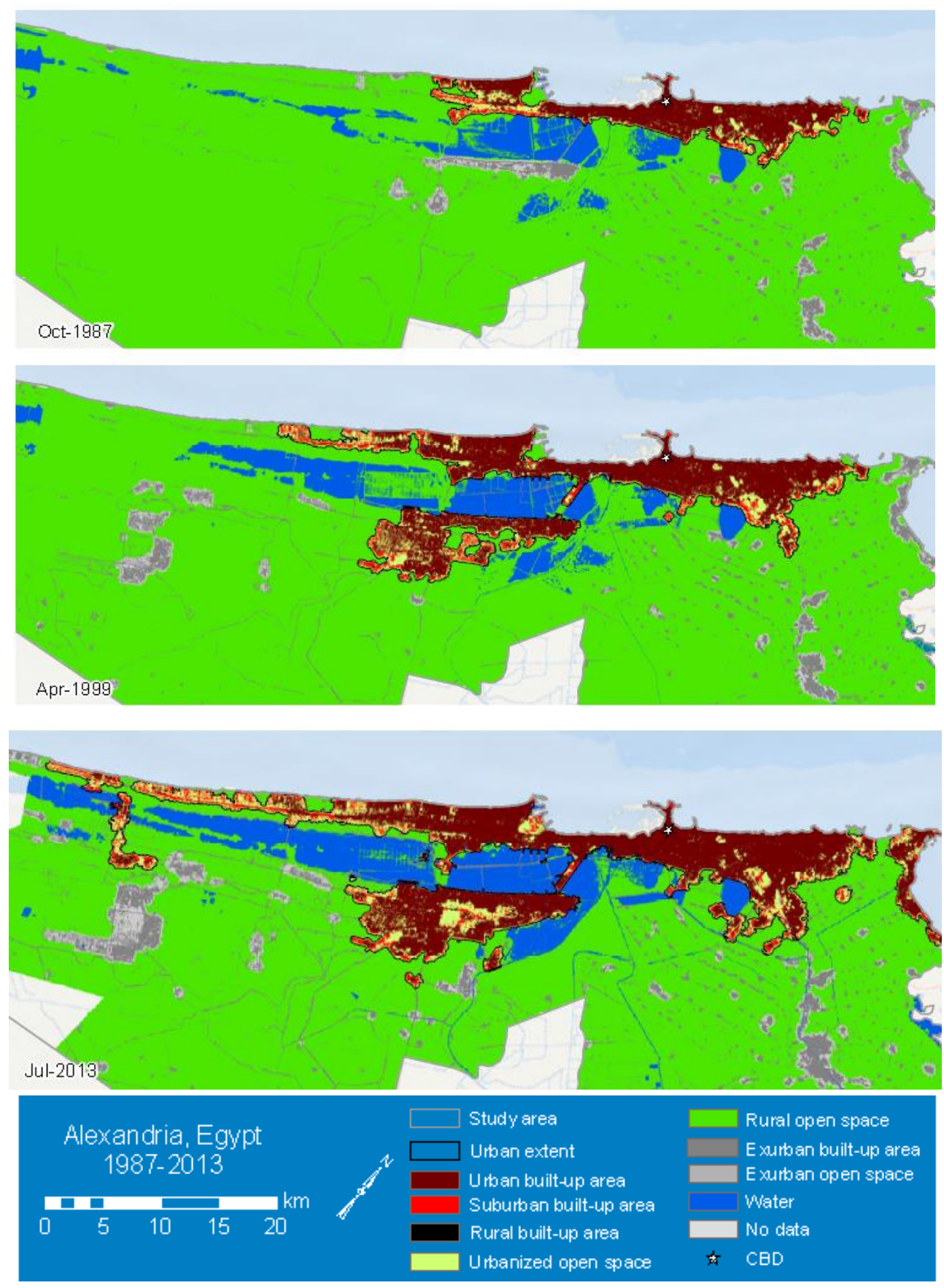

Fig. 5: Alexandria master plan within three time periods [14] 
Table 5 Indicators of urban expansion of Alexandria city [14]

\begin{tabular}{lccccc}
\hline Indicators & & 1987 & 1999 & 2013 & $\begin{array}{c}\text { Amount of annual } \\
\text { change (\%) (1999-2013) }\end{array}$ \\
Population (person) & & $2,558,891$ & $3,132,780$ & $4,345,193$ & 2.3 \\
& Urban & 6,757 & 13,157 & 18,900 & 2.5 \\
Build-Up Area (ha) & Suburban & 998 & 2,234 & 3,625 & 3.4 \\
& Rural & 63 & 122 & 256 & 5.2 \\
Open Space Area (ha) & Total & 7,818 & 15,513 & 22,781 & 2.7 \\
Urban Extent Area (ha) & & 2,175 & 4,843 & 7,637 & 3.2 \\
& Total & 9,992 & 20,356 & 30,418 & 2.8 \\
Population Density (person/ha) & Built up & 327.3 & 201.9 & 190.7 & -0.4 \\
& Urban extent & 256.1 & 153.9 & 142.9 & -0.5 \\
Fragmentation & Saturation & 0.78 & 0.76 & 0.75 & -0.1 \\
& index & & & \\
Compactness & Openness index & 0.22 & 0.24 & 0.24 & 0 \\
& Proximity index & 0.42 & 0.43 & 0.41 & -0.3 \\
\hline & Cohesion index & 0.42 & 0.45 & 0.45 & -0.6 \\
\hline
\end{tabular}

\section{3-6 Khartoum city - Sudan}

Table 6 presents the most important indicators of Khartoum's urban expansion (Fig. 6) noting the following:

1) Urban extent: The population and area growth rate shows a large urban sprawl of $7.3 \%$ per annum, which is a very high rate in a compatible manner between the population and the land area. The table shows that the amount of change in the built-up area was the highest, reaching $10.5 \%$ while the built-up area in the suburban areas and rural areas increased by $1.2 \%$ and $4.2 \%$, also the area of open space increased by $3.2 \%$.

2) Population density: The table shows that the population density in the built-up area decreased by - $1.6 \%$ due to the urban sprawl and the horizontal expansion of the city, and the stability of density in the urban extent of the city.

3) Fragmentation: The saturation index indicates an increase of $1.7 \%$ as a result of the increase in the city's built-up area to $78 \%$. This has affected the openness index by $-2.6 \%$ despite the increase in the area of open space.

4) Compactness: The proximity and cohesion index indicates a reduction of $-0.2 \%$ and $-0.4 \%$ due to the urban sprawl of the city and its longitudinal expansion with the Nile river, more than the vertical expansion of the river, which increases the connection with the city center equally. 


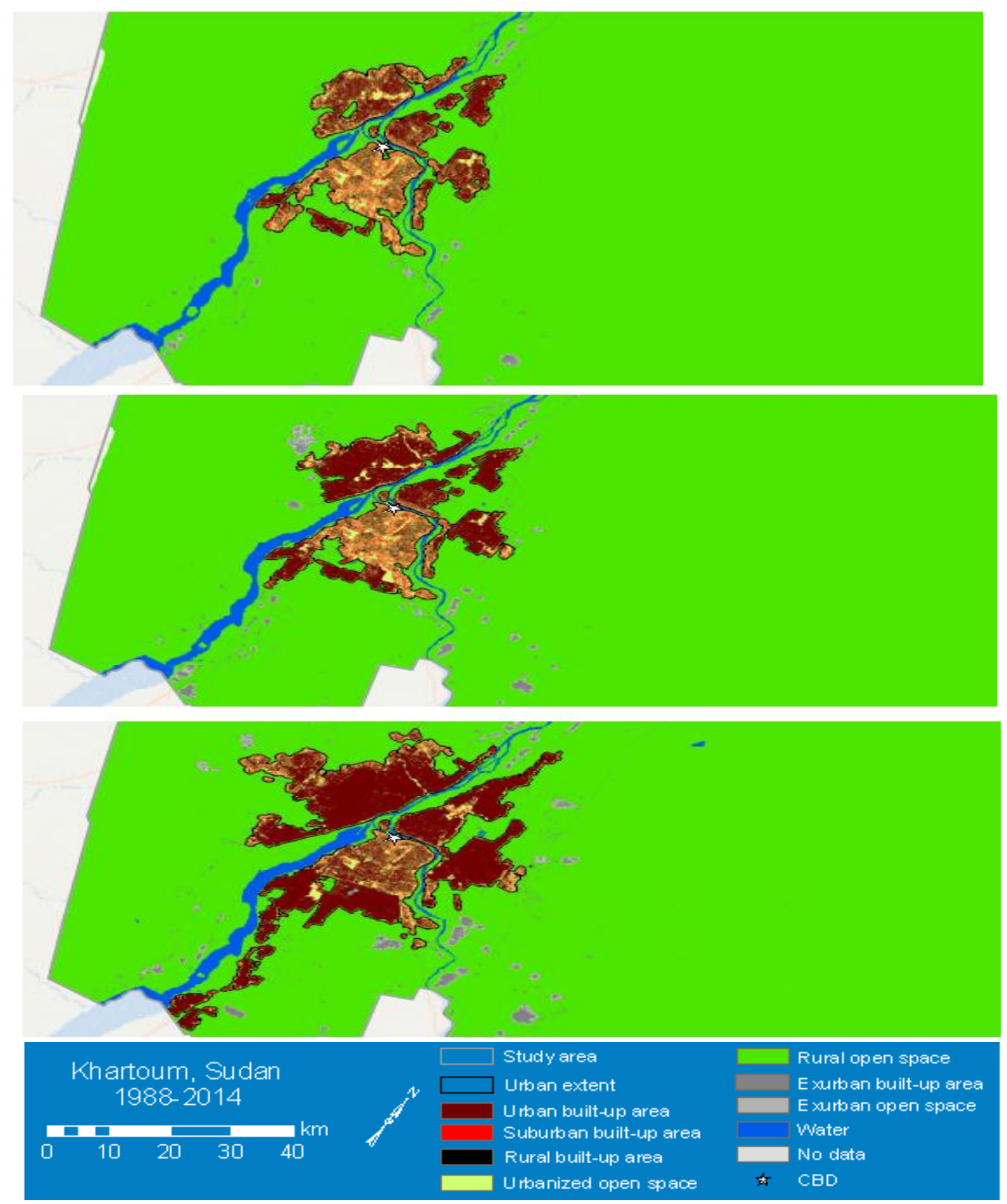

Fig. 6: Khartoum master plan within three time periods [14] 
Table 6 Indicators of urban expansion of Khartoum city [14]

\begin{tabular}{|c|c|c|c|c|c|}
\hline Indicators & & 1988 & 2000 & 2014 & $\begin{array}{c}\text { Amount of annual } \\
\text { change (\%) (2000-2014) }\end{array}$ \\
\hline Population (person) & & $1,253,183$ & $1,844,695$ & $5,061,792$ & 7.3 \\
\hline \multirow{4}{*}{ Build-Up Area (ha) } & Urban & 7,992 & 12,290 & 52,682 & 10.5 \\
\hline & Suburban & 4,712 & 4,493 & 5,283 & 1.2 \\
\hline & Rural & 185 & 172 & 307 & 4.2 \\
\hline & Total & 12,889 & 16,955 & 58,271 & 8.9 \\
\hline Open Space Area (ha) & & 10,141 & 10,254 & 16,026 & 3.2 \\
\hline Urban Extent Area (ha) & Total & 23,031 & 27,209 & 74,297 & 7.2 \\
\hline \multirow{2}{*}{ Population Density (person/ha) } & Built up & 97.2 & 108.8 & 86.9 & -1.6 \\
\hline & Urban extent & 54.4 & 67.8 & 68.1 & 0 \\
\hline \multirow{2}{*}{ Fragmentation } & $\begin{array}{l}\text { Saturation } \\
\text { index }\end{array}$ & 0.56 & 0.62 & 0.78 & 1.7 \\
\hline & Openness index & 0.39 & 0.26 & 0.18 & -2.6 \\
\hline \multirow{2}{*}{ Compactness } & Proximity index & 0.75 & 0.78 & 0.76 & -0.2 \\
\hline & Cohesion index & 0.75 & 0.78 & 0.74 & -0.4 \\
\hline
\end{tabular}

\section{3-7 Kairouan city - Tunisia}

Table 7 presents the most important indicators of Kairouan's urban expansion (Fig. 7) noting the following:

1) Urban extent: The population growth rate of Kairouan is $1.8 \%$, while the area growth rate is $0.5 \%$. This indicates the tendency towards the vertical expansion of the city and the urban infill of urban spaces. The table shows an increase in the built-up area in the suburban and rural areas and the decrease in its open space to a significant decrease of $7.6 \%$ and $-9.9 \%$, as well as the decrease in open spaces in the city by $3.9 \%$.

2) Population density: The table shows a very low density in the built-up area of $-0.1 \%$ and an increase in density of urban extent by $1.3 \%$, due to the increase of the built-up areas in the suburban and rural area of the city and the tendency of people to build in the edge of the city.

3) Fragmentation: The saturation index indicates that the city's built-up areas increased by $1.4 \%$ to reach an $80 \%$ saturation rate, with the openness index decreasing by $-3.8 \%$ due to the increase in built-up areas in rural and suburban areas.

4) Compactness: The proximity and cohesion index refer to the stability and compactly of the urban fabric and its regular distribution from the city center to all parts of the city equal to $93 \%$ and the shape of the city approaches the circular shape. 


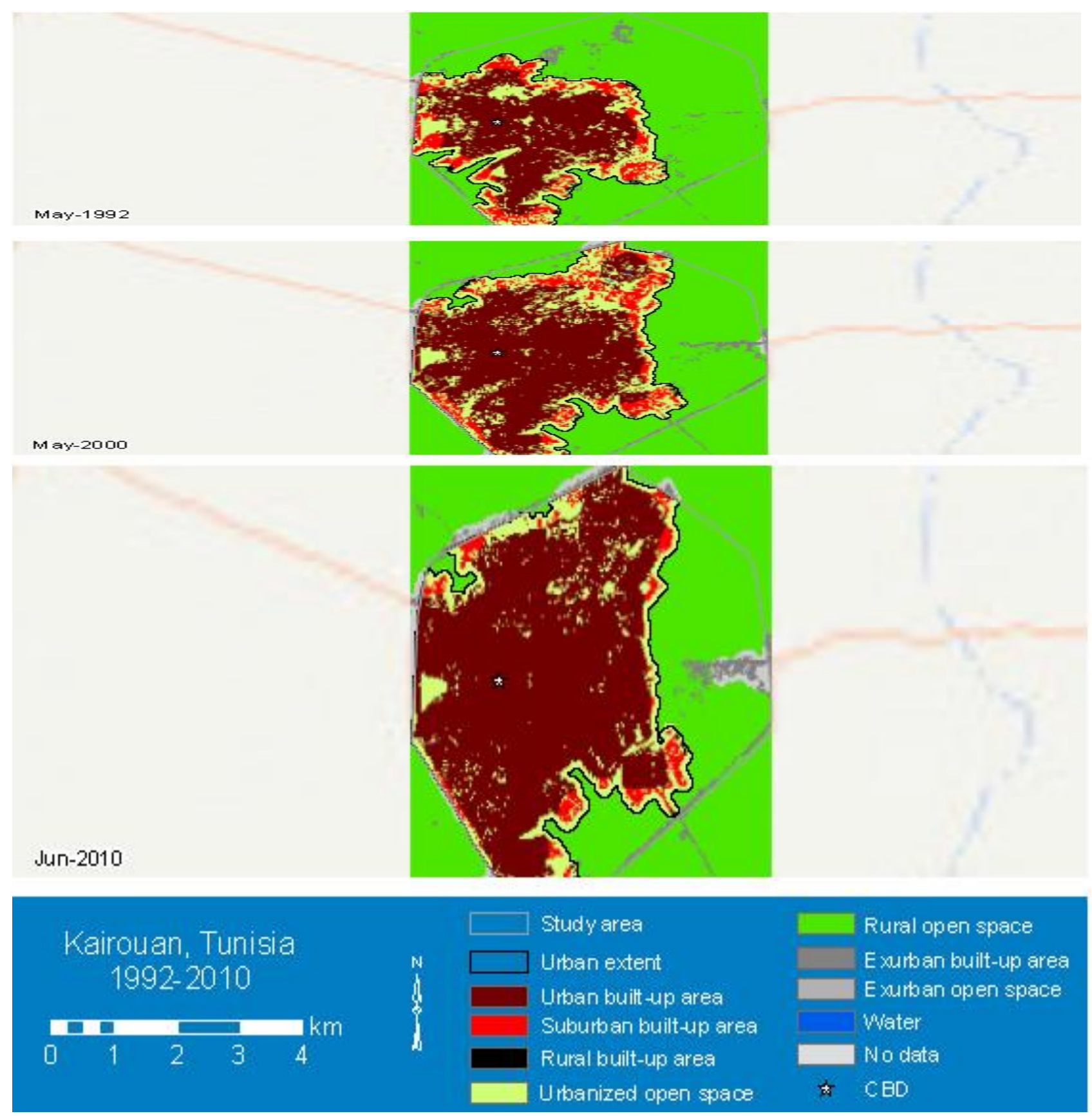

Fig. 7. Kairouan master plan within three time periods [14] 
Table 7 Indicators of urban expansion of Kairouan city [14]

\begin{tabular}{lccccc}
\hline Indicators & & 1992 & 2000 & 2010 & $\begin{array}{c}\text { Amount of annual } \\
\text { change (\%) (2000-2010) }\end{array}$ \\
Population (person) & & & & & \\
& Urban & 703 & 1,137 & 1,555 & 1.8 \\
Build-Up Area (ha) & Suburban & 188 & 218 & 102 & 3.1 \\
& Rural & 14 & 12 & 5 & -7.6 \\
Open Space Area (ha) & Total & 905 & 1,367 & 1,662 & -9.9 \\
Urban Extent Area (ha) & & 460 & 569 & 384 & 1.9 \\
& Total & 1,365 & 1,936 & 2,045 & -3.9 \\
Population Density (person/ha) & Built up & 94.8 & 77.5 & 76.8 & 0.5 \\
& Urban extent & 62.9 & 54.7 & 62.4 & -0.1 \\
Fragmentation & Saturation & 0.66 & 0.71 & 0.81 & 1.3 \\
& index & & & 127,570 & 1.4 \\
Compactness & Openness index & 0.32 & 0.27 & 0.18 & -3.8 \\
& Proximity index & 0.95 & 0.93 & 0.93 & 0 \\
\hline & Cohesion index & 0.94 & 0.92 & 0.92 & 0 \\
\hline
\end{tabular}

\section{3-8 Algeria city - Algeria}

Table 8 presents the most important indicators of Algeria's urban expansion (Fig. 8) noting the following:

1) Urban extent: The table shows that the population growth rate was $2.5 \%$, and the growth rate of the urban extent was $4 \%$, which is indicative of the city's expansion horizontally. I note that the built-up area is increasing by $4.2 \%$ and more than the total rate of $4 \%$. This indicates an increase in the built-up area at the expense of open space area in the suburban and rural area, with open space area increasing by $3.9 \%$.

2) Population density: The population density of the built-up area and the urban extent decreased by-1.6\% as a result of the horizontal expansion of the city.

3) Fragmentation: The saturation index indicates that the built-up area is stable and slightly increased by $0.1 \%$ to a value of $62 \%$. The openness index decreased by $0.7 \%$ to reach a value of $33 \%$. It is indicative of the lack of open space areas in the city.

4) Compactness: The Proximity and cohesion indicators indicate a small increase of $0.6 \%$ and try to approximate the shape of the city to the circular shape to reach more than $70 \%$. 

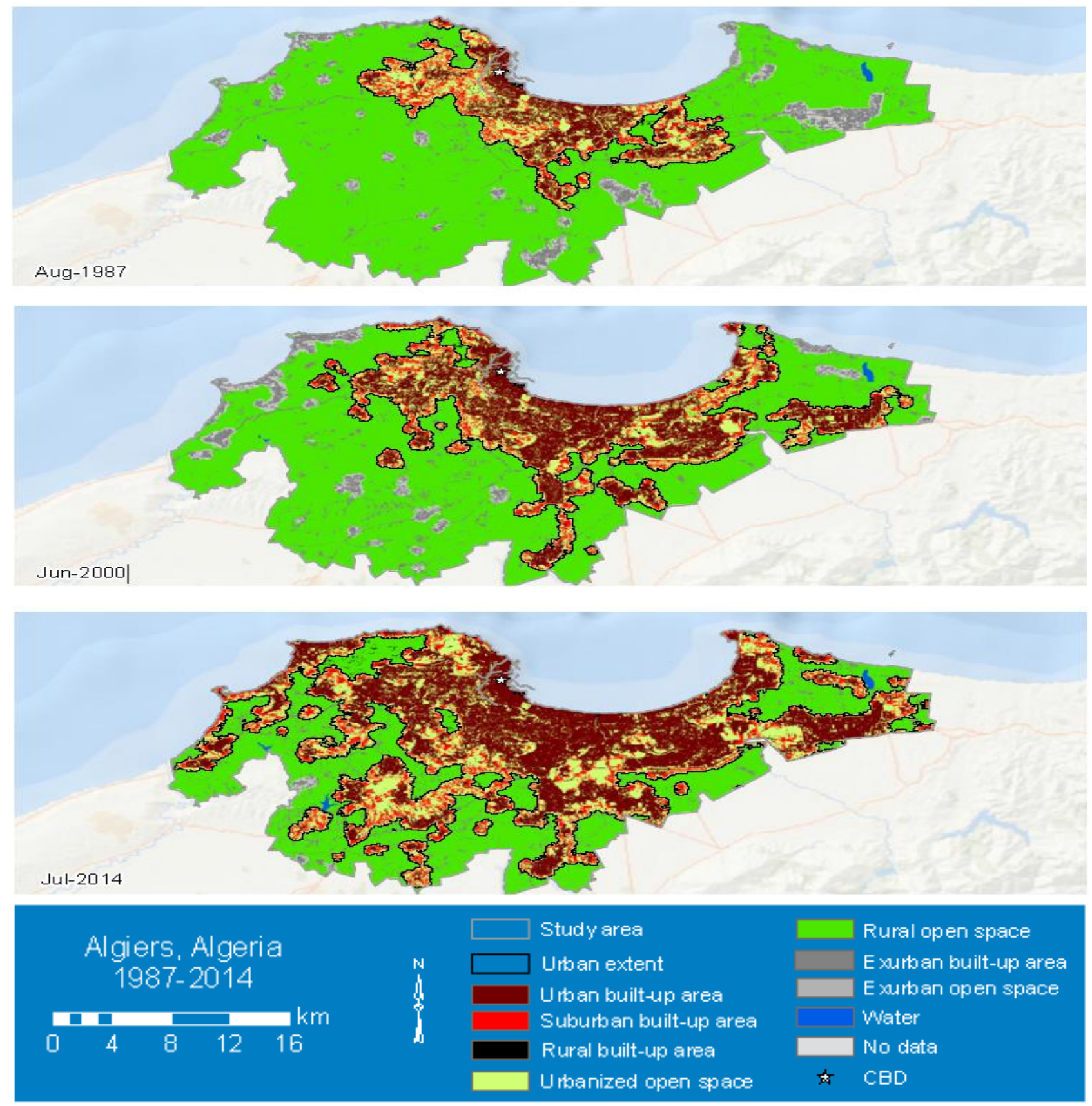

Fig. 8: Algeria master plan within three time periods [14] 
Table 8 Indicators of urban expansion of Algeria city [14]

\begin{tabular}{lccccc}
\hline Indicators & & 1987 & 2000 & 2014 & $\begin{array}{c}\text { Amount of annual } \\
\text { change (\%) (2000-2014) }\end{array}$ \\
Population (person) & & $1,535,735$ & $2,184,791$ & $3,085,561$ & 2.5 \\
& Urban & 4,440 & 11,382 & 20,537 & 4.2 \\
Build-Up Area (ha) & Suburban & 2,810 & 3,959 & 6,835 & 3.9 \\
& Rural & 196 & 298 & 426 & 2.5 \\
Open Space Area (ha) & Total & 7,446 & 15,639 & 27,798 & 4.1 \\
Urban Extent Area (ha) & & 6,458 & 9,801 & 17,014 & 3.9 \\
& Total & 13,903 & 25,439 & 44,812 & 4 \\
Population Density (person/ha) & Built up & 206.3 & 139.7 & 111.0 & -1.6 \\
& Urban extent & 110.5 & 85.9 & 68.9 & -1.6 \\
Fragmentation & Saturation & 0.54 & 0.61 & 0.62 & 0.1 \\
& index & & 0.37 & 0.33 & -0.7 \\
Compactness & Openness index & 0.45 & 0.37 & 0.6 \\
& Proximity index & 0.69 & 0.66 & 0.72 & 0.6 \\
\hline
\end{tabular}

\section{3-9 Marrakech city-Morocco}

Table 9 presents the most important indicators of Marrakech's urban expansion (Fig. 9) noting the following:

1) Urban extent: The population growth rate was $3.3 \%$ while the annual change in urban area was $5.6 \%$, which indicates the expansion of the city horizontally. This increase was greater for the open space areas by $7.1 \%$ while the total built-up area increased by $5 \%$. The table presents that the largest percentage increase in the built-up area was $10.1 \%$ in the rural area, followed by the suburban area by $7.2 \%$ and $4.6 \%$ for the urban area, which refers to the expansion and building in the suburban and rural areas of the city.

2) Population density: The population density in the built-up area decreased by $-1.7 \%$ and the decline in urban extent by $2.2 \%$, which indicates the city's horizontal expansion and spread over large areas of the city's macro level.

3) Fragmentation: The saturation index refers to a decrease of- $0.6 \%$ as a result of the decline of the city's built-up area compared to the increase in open space areas in the city, which was affected by a $1.3 \%$ increase in the openness index and an increase in urban spaces in the city of Marrakech.

4) Compactness: The proximity and consistency index indicates a decrease of $-2 \%$ and $-2.1 \%$ as a result of the expansion of longitudinal stretches far from the city center and the elongation of the city's urban form and its distance from the circular shape. 

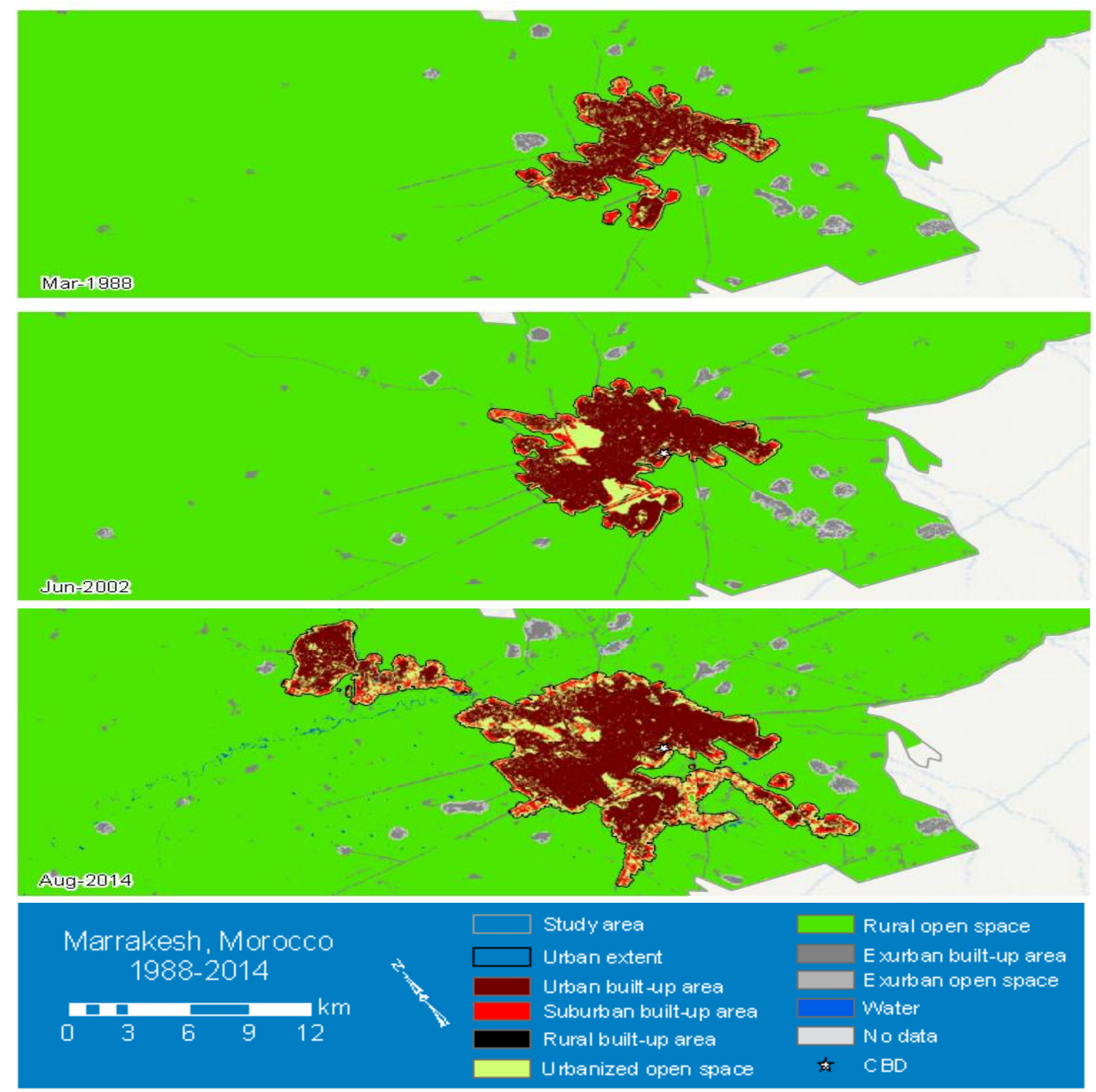

Fig. 9. Marrakech master plan within three time periods [14] 
Table 9 Indicators of urban expansion of Marrakech city [14]

\begin{tabular}{|c|c|c|c|c|c|}
\hline Indicators & & 1988 & 2002 & 2014 & $\begin{array}{c}\text { Amount of annual } \\
\text { change }(\%)(2002-2014)\end{array}$ \\
\hline Population (person) & & 371,585 & 514,030 & 770,422 & 3.3 \\
\hline \multirow{4}{*}{ Build-Up Area (ha) } & Urban & 3,125 & 4,735 & 8,252 & 4.6 \\
\hline & Suburban & 666 & 676 & 1,622 & 7.2 \\
\hline & Rural & 32 & 36 & 125 & 10.1 \\
\hline & Total & 3,823 & 5,447 & 9,999 & 5 \\
\hline Open Space Area (ha) & & 1,339 & 1,813 & 4,303 & 7.1 \\
\hline Urban Extent Area (ha) & Total & 5,162 & 7,260 & 14,302 & 5.6 \\
\hline \multirow{2}{*}{ Population Density (person/ha) } & Built up & 97.2 & 94.4 & 77.1 & -1.7 \\
\hline & Urban extent & 72.0 & 70.8 & 53.9 & -2.2 \\
\hline \multirow{2}{*}{ Fragmentation } & $\begin{array}{l}\text { Saturation } \\
\text { index }\end{array}$ & 0.74 & 0.75 & 0.70 & -0.6 \\
\hline & Openness index & 0.28 & 0.22 & 0.26 & 1.3 \\
\hline \multirow{2}{*}{ Compactness } & Proximity index & 0.82 & 0.92 & 0.71 & -2 \\
\hline & Cohesion index & 0.81 & 0.9 & 0.7 & -2.1 \\
\hline
\end{tabular}

\section{Conclusions}

1) The annual population growth rate with the annual area growth rate indexes, show that the lower the population growth rate than the growth rate of the area, the urban expansion of the city is horizontal and vice versa, and this affects the population density as follows:

- Population density decreases if the population growth rate is lower than the rate of growth of the area.

- Population density rises if the population growth rate is higher than the rate of growth of the area.

2) Built up area is related to the saturation index and as follows:

- The saturation index is positive if the annual change in the urban area is greater than the annual change of the suburban and rural areas within the built-up area.

- The saturation index is negative if the annual change in the urban area is smaller than the annual change of the suburban and rural areas within the built-up area.

3) The relationship between the saturation and the openness index is inverse, and the saturation index is linked to the built-up area, and the openness index is linked to the open space area.

4) The relationship between the proximity and cohesion index is direct.

5) Arab cities are divided in terms of the relationship of annual population growth and the growth of the annual area into:

- Population growth is greater than area growth: Cities are dependent on urban expansion by increasing density, infilling the urban spaces and vertical expansion in a city such as Baghdad and Kairouan.

- Population growth is much smaller than the area growth: Cities that are largely dependent on urban sprawl and horizontal expansion, such as Cairo and Sana'a city.

- $\quad$ Population growth and area growth are very high: Cities with high population growth rates with excessive urban sprawl such as Khartoum, Riyadh and Marrakech city.

- Population growth is smaller than area growth: Cities are characterized by a convergence of population and spatial growth rates and are based on acceptable horizontal expansion such as Alexandria and Algeria city.

\section{Recommendations}

1) The adoption of the compactness index (proximity and cohesion) by more than $85 \%$ to form the city closer to the circular shape, which ensures equal and proximity distances from the city center to achieve easy access to various events and activities, and the fragmentation index (saturation and openness) is between $30-35 \%$ for the openness index and $65-70 \%$ for the saturation index to achieve a balance in the mass and the void in the city, this is comparable to the planning of sustainable cities in the world.

2) Preparing a manual for indicators of urban expansion by specialists, including all indicators adopted when updating or preparing the master plans. 
3) Urge decision-makers to focus on the implementation of sustainability policies and sustainable urban expansion when updating or preparing the master plans through the enactment of urban laws and legislation that guarantee and require the implementation of the policy.

4) Preparing sustainable indicators for cities by specialists and then applying them to Arab cities to identify the gap between the reality of the cities and sustainable indicators, to develop solutions and gradually shift towards sustainable cities.

\section{References}

[1] Bay, J. H. Philip and Lehmann, Steffen, Growing Compact: Urban Form, Density and Sustainability. Routledge Taylor \& Francis Group, 2017, p. 4.

[2] United Nations, World Urbanization Prospects: The 2014 Revision. Department of Economic and Social Affairs, Population Division, New York, USA, 2015, p. 1. https://population.un.org/wup/Publications/Files/WUP2014-Report.pdf

[3] Angel, Shlomo, Sheppard, C. Stephen and C. Daniel , The Dynamics of Global Urban Expansion. Department of Transport and Urban Development, The World Bank, Washington D.C., USA, 2005, p. 49.

[4] Schneider, A., Friedl, M. A. and D. Potere, “A New Map of Global Urban Extent from MODIS Satellite Data” in IOP Publishing, Environmental Research Letters, vol. 4, no. 4, pp. 1-11, October 2009.

[5] Angel, Shlomo, Sheppard, C. Stephen and C. Daniel L., The Dynamics of Global Urban Expansion. Department of Transport and Urban Development, The World Bank, Washington D.C., USA, 2005, p. 1.

[6] Bay, J. H. Philip and Lehmann, Steffen, Growing Compact: Urban Form, Density and Sustainability. Routledge Toaylor \& Francis Group, 2017, p. 4.

[7] Lehmann, S., What is density?. Wiley-Blackwell Encyclopedia of Urban and Regional Studies, Wiley, Oxford, 2017.

[8] Angel, Shlomo, Parent, Jason and Civco, Daniel L “The Fragmentation of Urban Landscapes: Global Evidence of a Key Attribute of the Spatial Structure of Cities, 1990-2000 SAGE, Environment and Urbanization," International Institute for Environment and Development (IIED), Vol 24, Issue 1, pp. 249-283, 2012.

[9] Angel, Shlomo, Sheppard, C. Stephen and Civco. Daniel, The Dynamics of Global Urban Expansion. Department of Transport and Urban Development, The World Bank, Washington D.C., USA, 2005, p. 250.

[10] Jacobson, Alma, A Cohesive Downtown from a Knowledge City Perspective - A Study in Urban Planning. Thesis, School of Engineering, University of Jönköping, Sweden, 2012, p. 13.

[11] Angel, Shlomo, Sheppard, C. Stephen and C. Daniel, The Dynamics of Global Urban Expansion. Department of Transport and Urban Development, The World Bank, Washington D.C., USA, 2005, p. 10.

[12] Angel, Shlomo, Sheppard, C. Stephen and C. Daniel L., The Dynamics of Global Urban Expansion. Department of Transport and Urban Development, The World Bank, Washington D.C., USA, 2005, p. 68.

[13] Jacobson, Alma, A Cohesive Downtown from a Knowledge City Perspective - A Study in Urban Planning. Thesis, School of Engineering, University of Jönköping, Sweden, 2012, p. 25.

[14] Angel, Shlomo, Blei, M. Alejandro, Parent, Jason, H. Lamson, Patrick and Sánchez, N. Galarza, Atlas of Urban Expansion. 2016 Edition, Volume 1: Areas and Densities" New York University, UN-Habitat and the Lincoln Institute of Land Policy, 2016, p.p. 42-341. 